\title{
Electronic books in public libraries: a feasibility study for developing usage models for Web-based and hardware-based electronic books
}

Final Report, August 2004

The primary project contacts are:

James Dearnley J.A.Dearnley@lboro.ac.uk

Linda Berube Linda.berube@cambridgeshire.gov.uk

Martin Palmer martin.palmer@essexcc.gov.uk

The project website can be found at:

http://www.lboro.ac.uk/departments/dis/disresearch/e-booksinpublib/index.html 


\section{Acknowledgements}

Many individuals have been helpful to us during the design and implementation of this research. We particularly wish to thank Frances Hendrix for her ongoing interest in the project, and also Dr Jim Parker for his friendly advice. The advisory board members gave us practical and important advice during the course of the research, and we are particularly indebted to lan Sutton (Blackburn with Darwen libraries) for his willingness to share information on the Total-IT-y programme. Penny Garrod also deserves thanks for publicising our research widely in her ongoing work at UKOLN.

We also wish to offer special thanks to Claudia Weissman and Steve Potash at OverDrive for their enthusiasm and help in setting up and maintaining the OverDrive collection. Our thanks also go to Coutts (ebrary's agent in the UK), for all their help during the last year.

Finally, our thanks go to all the librarians at Essex who took part in this research for their help and suggestions. 


\section{Contents}

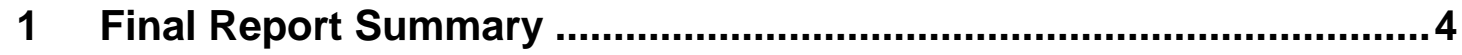

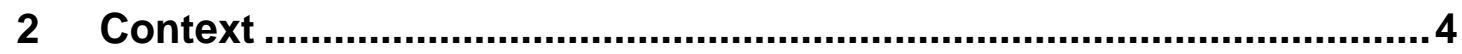

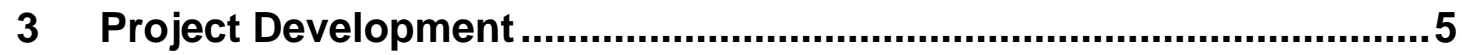

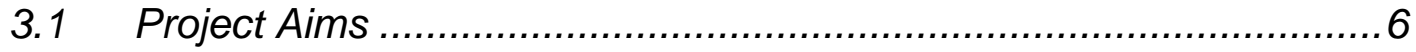

3.2 Project Objectives............................................................. 6

3.3 Project Planning: Issues for Consideration ...............................6 6

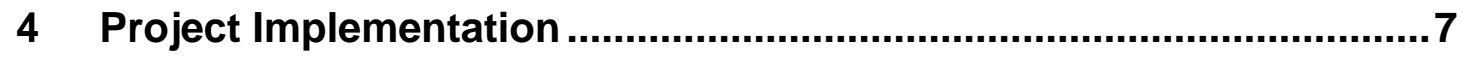

4.1 Project Management ............................................................ 7

4.2 Ebook Advisory Group ...................................................... 8

4.3 Orientation and Training of Staff in Essex ................................. 9

4.4 Identification and Recruitment of Target Audiences ......................10

4.5 Selection of and Negotiation with Suppliers................................ 11

4.6 Procurement -Software Suppliers.......................................... 11

$4.7 \quad$ Content acquisition ......................................................... 12

$4.8 \quad$ Technical Implementation .................................................. 14

4.9 Distribution of PDAs ..................................................... 14

4.10 Promotion .................................................................... 15

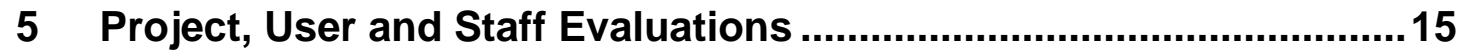

5.1 Project Evaluation Critical Success Factors ............................... 15

5.2 User and Staff Evaluation Aims and Methods ............................ 16

5.3 User perceptions of the ebook collections. ...............................17

5.4 Professional perceptions of the ebook collections........................22

5.5 User perceptions of the ebook collections. ................................ 25

5.6 Quantitative data on the OverDrive and Ebrary collections. ............25

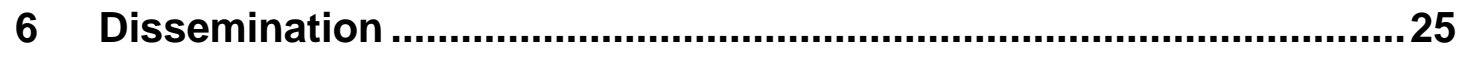

7 Final Report: Summary of Findings ..............................................26

8 Guidelines for Public Library Implementation ...............................28 


\section{Final Report Summary}

This final report considers the background and implementation of a project that introduced electronic book (ebook) collections to Essex Public Libraries in 2004. The research considered ebook collections available for borrowing on a PDA (HP iPAQ) and collections downloadable on to the borrower's PDA or PC (OverDrive, ebrary).

The project, a partnership consisting of Loughborough University, Essex Public Libraries, and the Co-East Management Team, set out to achieve the following objectives:

- Introduction of an ebook collection for public library patrons at the Co-East partner library, Essex;

- Documentation and analysis of the reactions to ebook borrowing from library staff and their patrons;

- Documentation and analysis of the reactions to portable handheld ebooks held on iPAQ devices and Web-based ebook delivery (OverDrive, ebrary) from library staff and their patrons;

- Documentation and analysis of various issues concerning selection of ebook titles, as well as use of ebook devices in public libraries;

- Raising the awareness of issues concerning ebooks within the digital library environment. (Appendix 1)

Specifically, this report describes and analyses a range of findings from the project for the period from January to June 2004, during which time both hand-held and webbased collections were implemented and made available to the public. Moreover, it offers guidelines to other public library authorities considering the adoption of ebook collections and mobile technology. Because Essex has adopted the e-book collections procured during the project as a sustained service, the Project Team will continue to gather data and information on the web-based ebook collections provided by OverDrive and ebrary. We will publish additional findings and case studies in a supplement in early 2005.

\section{Context}

In the UK, public library provision of ebook software and hardware devices has not been widespread, although there has been a degree of interest and experimentation in ebook collection development. Research undertaken for Resource (now, Museums, Libraries, and Archives Council) in April 2002 indicated that ebook provision (CD-ROM ebooks) in the 116 libraries surveyed was rather limited, and only one public library (Blackburn with Darwen) was then actively offering handheld ebooks and Microsoft Reader titles'. Blackburn with Darwen Libraries continued to develop their 'Total-IT-y' service offering text and audio ebooks after receiving an $£ 80,000$ award from the New Opportunities People's Network Excellence Fundii. They launched their PDA-based ebook collections as a 'mainstream' part of the service in April 2004. A short report written by lan Sutton (project manager of TotalIT-y, and a member of this project's Advisory Board) considering the ebook collection 
at Blackburn with Darwen is included in Appendix 11 for context. Several conclusions reached in this research in relation to PDA devices, collections and staff training correlate with the experience at Blackburn with Darwen.

Richmond Libraries also successfully launched an ebook collection using NetLibrary and Safari following an award from the People's Network Excellence Fund in 2002 2 ii. Monica Vidana, the project manager (and also a member of this project's Advisory Board) reflected on the collections in an article for Update in May $2003^{\text {iv }}$.

Leicestershire Libraries also conducted trials using handheld Rocket ebooks between 2001 and 2002 - findings from that study have also been published ${ }^{\mathrm{v}}$.

The reasons for relatively low uptake of ebooks in the UK are significant. Commercial ebook collections are available in the UK, but there has been a distinct hesitation connected to the lack of appropriate models through which to introduce them effectively to the public.

Concerns include:

- $\quad$ lack of content and collection development of specific UK-interest titles ;

- $\quad$ network security;

- $\quad$ expense (e.g. cost of introducing ebook collections versus maintaining and developing existing pbook collections);

- $\quad$ licensing and stock supply models;

- $\quad$ lack of content and subtstantive ebook collections;

- $\quad$ maintenance (e.g keeping iPAQ devices functional); and

- $\quad$ usability (e.g. offering a service which people find useful and as enjoyable as reading from pbooks).

Conversely, and as this research demonstrates to an extent, introducing ebook collections offers a range of potential benefits to public libararies. These include raising the public library profile as a leading edge service provider and offering a collection which is available on 24-hour access to those who have Internet connections at home. The iPAQ trial which we carried out as part of this research indicated that many individuals enjoyed reading ebooks even where there were concerns about the hardware being used (generally in regard to screen size and battery life). The participants in the iPAQ trial were by no means hostile to ebooks, but they were not enamoured with the hardware. Perhaps the most telling point from the research thus far has been the need to present ebook collections as a supplementary service to exisiting p-book collections, and not intimate that ebooks in any way supplant existing collections.

\section{Project Development}

To help address the gap in UK public library ebook provision, Co-East and Loughborough University aimed to develop workable guidelines for introducing and maintaining ebook collections. A submission to the LASER Foundation in autumn 2002, under the 'E-content for public libraries' theme, aimed to evaluate ebook implementation and usage at a Co-East partner library authority, Essex, over a one year period, starting in April 2003. Ebook provision included: 
- $\quad$ lending IPAQ PDA devices with a number of ebook titles loaded, to specific groups of users;

- $\quad$ providing PC-based Web access to two ebook collections to a range of library patrons. Users were offered ebooks for download based on Adobe 6 and Palm‘E-book’ formats.

\subsection{Project Aims}

This project aimed to:

- $\quad$ develop and evaluate ebook collections of titles appropriate for general public library use, as well as for special user groups;

- $\quad$ ascertain the relative merits of three ebook formats in terms of adoption and management of ebook collections;

- $\quad$ consider the implications of introducing ebooks to public library services (e.g. staffing, budgeting, marketing);

- $\quad$ make sensible recommendations regarding the adoption, management and development of ebook collections in public libraries.

\subsection{Project Objectives}

The project objectives were to:

- $\quad$ introduce an ebook collection for public library patrons at the Co-East partner library authority, Essex;

- $\quad$ document and analyse the reactions to ebook lending from library staff and their patrons;

- $\quad$ document and analyse reactions to portable handheld ebooks and Webbased product from library staff and their patrons;

- $\quad$ document and analyse various issues concerning selection of ebook titles, as well as use of ebook devices and public libraries;

- $\quad$ raise awareness of the issues concerning ebooks within the digital library environment.

\subsection{Project Planning: Issues for Consideration}

During the development and planning of the project proposal, the project partners identified that the following issues needed to be addressed:

\subsubsection{Demand}

At the time of considering the project, in Essex particularly, there did not appear to be any demand. Essentially, users were not asking librarians for ebook content, either in focus groups, questionnaires, or in daily transactions.

Ebooks and ebook devices were relatively unknown to the UK public, in general.

\subsubsection{Content}

Another concern was UK-specific and/or appropriate content for public users. The most well-known UK aggregator service's collections targeted universities, with a very limited supply of fiction titles. The project partners knew that finding content which would appeal to public library users would be a challenge 
Various studies of ebooks in the US confirmed not only the poor selection of fiction, especially best sellers popular with public library users, but also the lack of inclination to read fiction in ebook format ${ }^{\mathrm{vi}}$. Even more problematic was the selection for children and special user groups. Most research had confirmed the ebook format as conducive to searches for specific information, textbook use ${ }^{\text {vii. }}$.

\subsubsection{Mobile Technology (PDAs-Personal Digital Assistants)}

The project team had posed itself an additional challenge in piloting a service which combined the use of PDAs with reading ebooks. PDA use has gained in popularity, especially in university health libraries in the United States ${ }^{\text {viii. }}$

For public libraries, PDA use targeted at special user groups, such as housebound users, would provide a means to develop inclusive services to remote users.

The project team also considered the different formats as well as the different types of handheld devices. Initially, dedicated ebook devices were considered, but their lack of availability in the UK combined with the growing market for convergent technology resulted in the decision to go with PDAs. In addition, the project would provide PC-based ebooks through an aggregator service.

\subsubsection{Supply Model}

The two current models for ebook acquisition and supply are 'by title' and 'by collection.' While the title model allowed for a more targeted collection, it could only be circulated in the manner of a print book: one copy per user at a time. Buying collections, instead of individual titles, means paying for considerably more content than will be used, but usually allowed for concurrent access to titles. The entire collection would always be available.

\subsubsection{Suppliers}

As ebook implementation remains relatively new to all libraries in the UK, most of the suppliers were US-based. A few of these, such as NetLibrary and ebrary did have offices or distributors in the UK, while others, such as OverDrive, required direct negotiation with offices in the US. A significant issue with dealing with US-based suppliers concerned licensing and pricing models more aligned to US models of library provision.

\section{Project Implementation}

In order to achieve the project objectives, as well as to resolve the various issues, a project plan, including the following significant tasks, was devised:

\subsection{Project Management}

The Co-East Management Team, consisting of Linda Berube and Joanne John, were responsible for the practical aspects of managing the project including project administration and reporting, assistance with procurement and dissemination, in addition to:

- $\quad$ Training librarians to use the devices/software and providing basic models of operation; 
- $\quad$ Liaising with and supporting Essex County Libraries project officer, Martin Palmer, and Essex Project Team, regarding training and collection of data;

- $\quad$ Maintaining pertinent project management documentation, and liasing with project stakeholders to identify and resolve problems;

- $\quad$ Creating database for the assembly of quantitative and qualitative datadata;

- $\quad$ Reporting back on progress to Co-East partners, and planning future development based on outcomes.

The Essex Project Team, led by project officer Martin Palmer, handled the day to day implementation of ebooks software and hardware, including:

- $\quad$ Recruiting and training staff champions, specifically mobile managers, volunteers, etc.;

- $\quad$ Providing input in the development of guides and evaluation instruments;

- $\quad$ Selecting and downloading titles to PDAs according to users' requests;

- $\quad$ Identifying and recruiting additional special user groups outside those named in the original project proposal;

- $\quad$ Collecting evaluation feedback;

- $\quad$ Day to day management of ebook collection.

In addition, the Essex Stock team developed the OverDrive collections, and initially downloaded ebook titles for housebound users. The Essex Project Team included Elaine Adams, Janice Waugh, Jill Palmer and Lee Shelsher from the Loughton and Saffron Walden libraries.

The Department of Information Science at Loughborough University Team, consisting of James Dearnley, Anne Morris, and Cliff McKnight, were responsible for the following:

- Undertaking literature reviews and keeping abreast of developments in the ebook field;

- $\quad$ Designing and piloting questionnaires and helping to conduct focus groups with library staff and library patrons;

- $\quad$ Designing research instruments and publishing findings for research outputs;

- $\quad$ Maintaining a project Web site, including a Weblog;

- $\quad$ Submitting project and budget reports.

\subsection{Ebook Advisory Group}

The Advisory Group provided both a steer as well as a national and cross-domain context for project implementation. For instance, through the group, we were able to learn of the progress in the other two major public library implementations in Richmond and Blackburn. In addition, the JISC representative was able to report on the progress of the JISC projects in academic libraries, running concurrent to the LASER project, including E-Book Mapping; Strategy and Vision for E-Textbooks; Marketing and Promotion of E-Books; Free E-books ${ }^{\text {ix }}$.

The terms of reference for the group were as follows:

- Based on individual expertise, to advise the project team on content, usability, functionality of ebooks collections, titles, devices and suppliers;

- To provide feedback on the user consultation plan, including questionnaires and other research instruments;

- To participate in promotional activities; 
- Where relevant, to provide any feedback (usage statistics, evaluation findings) from other ebook implementations, especially those using different suppliers.

\section{Group Representatives:}

\begin{tabular}{|c|c|}
\hline James Dearnley & Loughborough University \\
\hline Linda Berube & Co-East \\
\hline Martin Palmer & Essex Public Libraries \\
\hline Anne Morris & Loughborough University \\
\hline Cliff McKnight & Loughborough University \\
\hline Joanne John & Co-East \\
\hline Ian Sutton & Blackburn \\
\hline Monica Vidana & Richmond \\
\hline $\begin{array}{l}\text { Hazel } \\
\text { Woodward }\end{array}$ & Cranfield/JISC \\
\hline Jim Parker & Public Lending Right \\
\hline Chris Hayes & Southend/Co-East \\
\hline Penny Garrod & UKOLN \\
\hline Pirkko West & $\begin{array}{l}\text { Central Buying } \\
\text { Consortium/Kent }\end{array}$ \\
\hline
\end{tabular}

The project advisory board met on May $12^{\text {th }} 2003$, and again on February $10^{\text {th }} 2004$. Both meetings proved to be most useful, with all the participants able to bring their experience to bear on the research. Actions included:

- $\quad$ Developing a common data collection procedure between this research and the People's Network funded research at Blackburn with Darwen. It was felt that a joint approach to data collection would provide public libraries with a greater body of knowledge on which to consider ebook collections.

- $\quad$ Circulating a questionnaire produced at the Department of Information Science for evaluating iPAQ ebook collections in Essex to lan Sutton at Blackburn for his perusal. Members of the group were also invited to look at Blackburn's collection.

- $\quad$ Exploring the possibility of joint event for JISC/Richmond/Essex/Blackburn to provide for higher visibility for the project and its outcomes.

- $\quad$ Informing the Central Buying Consortium (CBC) of progress via their representative on the board, Pirkko West.

\subsection{Orientation and Training of Staff in Essex}

One of the biggest challenges to implementing any new service or content, especially one as fraught as ebooks with technical and cultural issues, is creating an enthusiastic staff base. If the staff are not promoting the service, explicitly and implicitly, then users will not be inclined to use the service. 
Creating staff champions was an important objective for the project, and to that end the Project Team held a session with the Essex Project Staff which covered the following areas:

- $\quad$ Background;

- $\quad$ Software;

- Hardware, including demonstrations of the PDA;

- Issues and recommendations for resolution. (Appendix 2)

Providing the staff with a formal orientation session also gave them support for cascading training to other staff members involved directly with users, for instance the mobile managers. In addition, the Project Team held regular meetings with the Essex project staff, who contributed to planning and evaluation in the following ways:

- $\quad$ Suggesting and approaching different user groups: for instance, trialing PDAs with day care centres, and a village where a branch library had been closed;

- $\quad$ Liasing with different volunteer groups to deliver the service: this required a sensitive and supportive approach in some cases as this technology was both new and alien to some of the volunteer groups;

- $\quad$ Providing input into the development of the questionnaire and support materials, such as the PDA manuals.

The Project Team found the Essex Project staff to be enthusiastic and willing to negotiate with the challenges of the new technology.

\subsection{Identification and Recruitment of Target Audiences}

At the outset of the project, there was very little evidence of use of mobile devices by public libraries in the UK. What we wanted to test in Essex was the use of the technology to help specific users overcome barriers to library content, in essence matching the service to the user.

The original project plan proposed targeting such groups as housebound people, mobile users, and visually-impaired people. During the project, the Essex team successfully recruited housebound and mobile users. In fact, interest in the project made for a queue of users waiting to trial the PDAs. Each of these users was supplied with forms, asking for their reading and font size preferences (Appendix 7).

As mentioned in the above section, the Essex project staff were especially creative in seeking out opportunities for including different types of users in the project. In addition, some initial publicity pulled in some self-selected users.

\section{Visually-Impaired Users}

The Project Team encountered problems early on with provision for visually-impaired people. It had originally been envisioned that advanced graphic and audio software could be used in conjunction with the PDAs purchased for the project. Unfortunately, the version of the PDAs did not accommodate the preferred software, and as the level of funding made it impossible to purchase upgrades, it was decided that this group could not be effectively included in the project.

Interestingly, this was one area where the assumptions of the Project Team were proved incorrect. Some of the self-selected users were indeed visually-impaired, and 
yet were still using the Overdrive service for ebooks. It turned out that they were making use of the Adobe 6 "read aloud" facility on their PCs (this is not available on the PDA version of Adobe) , a format that the Project Team had initially dismissed as of poor quality. However true that assessment might be, we learned that when there is not a lot of choice, users will make do with what is available.

\subsection{Selection of and Negotiation with Suppliers}

During the period of project proposal development, the Project Team looked at a number of content aggregators, including NetLibrary; ebrary; OverDrive; Safari; and DolphinUK. There was no one perfect supplier, and none provided collections that were aimed primarily at the UK-based general reader. In addition, licences and access were generally modelled on the pbook: one user, one title.

Initially, it was planned to evaluate Netlibrary and ebrary over a nine month period, and

ebrary was particularly attractive as it offered concurrent access to titles, an uncommon licensing arrangement among aggregators at that time.

Taking into consideration NetLibrary's collection, and the fact that Richmond was already trialing it, the group made a decision after discussions with OverDrive in April 2003 to adopt their product.

The choices for mobile technology included Palm; Pocket PC/Compaq iPAQ; Sony Zire etc. The Project Team was constrained by project funds, however, and settled on the iPAQ 1910. Although one of the cheaper PDAs on the market, it scored highly in terms of screen size, which was felt by the Project team to be a key requirement when reading ebooks.

\subsection{Procurement -Software Suppliers}

\section{OverDrive}

The target groups, consisting of remote users, required an ebook service which would allow for downloads onto mobile technology. OverDrive is currently the only aggregator in the market to provide this type of service. In addition, OverDrive's range of content, (especially fiction, offered on Adobe and Palm, and later in the project, MobiPocket) was well-matched to the needs of the target groups.

Subsequently, OverDrive agreed to offer their product at a considerable discount over a nine month period which enabled Essex to use a service which would otherwise have been far outside the scope of the project funding. OverDrive's product also includes the development and maintenance of a customised website that offers library patrons the ability to download titles onto their own PCs or mobile technology devices.

\section{ebrary}

Negotiations with ebrary exposed a number of important differences in approach between UK and US libraries and suppliers.

ebrary was originally selected for evaluation because its model exploits the technological advantages of ebooks far more effectively (from the librarian's point of view) than the traditional one copy/one loan arrangement, and because it gave the 
chance to trial a service not yet tested in a UK public library. ebrary agreed on the original bid to offer 27,114 accesses over a nine month period at a heavily discounted price, which again brought this service within the financial range of the project when it would otherwise not have been affordable. This offer was made via ebrary's agent in the UK, Coutts.

Unfortunately, the precise definition of what 27,114 accesses signified proved difficult to establish initially. ebrary's model for the UK is the same as that in the USA, where individual libraries purchase 'access'. In these cases, and similar to the academic environment where the number of full time equivalent students is used as the basis of the calculation, the number of patrons registered at a library is the figure used by ebrary to determine its fee.

In Essex, members are not allotted to specific libraries but instead have access to the entire service countywide. As a result, over 400,000 individuals would potentially have access to the ebrary service. This therefore posed an obvious question - how could access to ebrary be limited to 27,114 "hits"? The group had expected that 27,114 accesses could be made across the whole county, with the total simply offering an upper 'ceiling' for the research. This was originally thought to be the basis of the offer, but it then became clear that this was not what ebrary had envisaged. A solution explored by Martin Palmer was that ebrary could be offered from two branch libraries leading the iPAQ evaluations (Loughton and Saffron Walden), but the problem remained that library patrons 'belong' to the whole county, and not these two libraries.

So - in a parallel to the questions raised by the involvement of a third party ICT supplier, the problem faced with ebrary offers another initial research finding - that the ebrary ebook model cannot directly be ported from the USA to the UK in a way that makes economic sense from the UK public library point of view. This is particularly true for a larger authority such as Essex, where the significant financial commitment required would be difficult to justify in advance of any indication of the likely take-up by the public.

Moreover, the negotiation process has revealed issues with dealing with third party agents of foreign, and especially US, suppliers. The Project Team had originally thought that negotiation through a UK agent would enable things to be moved along more quickly and easily. However, the project negotiations have shown that dealing directly with US suppliers has allowed far more direct communications, decisionmaking, and problem-solving resulting in more clarity of contract terms.

\section{Hardware-PDAs}

In May 2003, twelve Hewlett Packard iPAQ 1910 devices to host OverDrive titles were purchased by Co-East as this model, selected by the team on the basis of screen size and affordability, was not available from Essex's ICT partner.

\subsection{Content acquisition}

\section{OverDrive}

An initial selection of 250 titles were selected from OverDrive's "ContentReserve" database. This was a mixture of fiction (mainly in the Palm Reader format) and nonfiction (mainly in the Adobe reader 6 format). 
Palm and Adobe were the only formats supported by OverDrive: Adobe was chosen for non-fiction primarily because it is essentially a direct copy of the paper version of the book, and so reproduces illustrations, charts and diagrams, unlike Palm.

The question of format is a key element in selection of ebooks. For example, although OverDrive provides a good range of material in these two formats, it does not supply anything in Microsoft Reader format. Similarly, towards the end of the project period, OverDrive switched from supporting Palm to MobiPocket: this was to do with both the increased range of material available from MobiPocket and the wider set of compatible hardware, including smartphones, that it can use.

As this change was introduced by OverDrive themselves, they undertook to replace titles that had already been bought in Palm free of charge, but the change illustrates the potential for ebooks that have been bought in good faith to become unusable and redundant very quickly. It also has obvious implications for the end user, who may well have to become acquainted with a whole new set of procedures for both downloading and navigation through ebooks.

More crucially, however, it poses a fundamental question for the librarian about how far it is desirable or necessary to buy titles in more than one format (most titles are available in a number of different formats). There is no real need to do this: the distinction noted above regarding preferring non-fiction in Adobe simply means using a different format for different categories, rather than duplicating titles in each. However, it is likely that there will be at least some potential users of the service who may prefer one format over another, or whose equipment will not support some formats, and who may therefore be deterred or prevented from using what the library is offering.

As in other areas of technology, format wars are nothing new, but they do provide an unwelcome element to the process of selecting not simply individual books, but also in deciding the whole basis of an ebook service.

As previously mentioned, access to the OverDrive service is provided through a custom-built website, which is accessible via (in this case) the Essex County Council website, making it possible to use the service remotely (authenticated by entering an Essex library card number) 24 hours a day, 7 days a week. The website also deals with all the Digital Rights Management/Copyright elements of ebook loans. Access is also possible directly from the library catalogue, but this element was not pursued as part of the project.

OverDrive ebooks are lent on a traditional lending library model: there is a 21 day loan, after which time the downloaded file simply becomes inactive, and the original ebook becomes available for loan again by another reader. Consequently, there is no need to "return" the ebook, and there are no fines. A maximum of three items can be held at any one time, and items can also be "held" if they are already in use readers are automatically notified by email when the ebook becomes available.

\section{ebrary}

In contrast to OverDrive's traditional model of one copy - one loan and the selection of individual titles, the ebrary approach involves buying access to a collection of titles, which then becomes available (via PC) to all members of the library service, allowing simultaneous access 24 hours a day, 7 days a week. As with OverDrive, access can be provided via the library catalogue, but again this was not pursued during the period of the project. 
Consequently, there is no selection of individual titles involved - simply selection of access to either the entire ebrary collection, or to one or more of the individual collections into which it can be divided.

For this project, we selected the "General Public Library" collection, which consisted of approximately 2,500 titles, almost entirely non-fiction. Again, in contrast to the OverDrive model, none of the traditional lending library limitations pertain, because the ebooks are not "lent" in that sense, but simply accessed. As a result, the whole concept of holds, for example, does not apply.

\subsection{Technical Implementation}

An important development in negotiation and installation of software has been the involvement of Essex's Corporate ICT partner. This experience, while delaying progress at certain points, has been constructive in that this is not a situation unique to Essex. Most public libraries in the UK, when seeking to develop and deliver new services, will need to build in additional project time to accommodate the processes and needs of their corporate ICT partners. Consultation with lan Sutton at Blackburn has confirmed a similar situation there with a different corporate partner, while Linda Berube has also experienced this on another project with yet a third company.

Some of the delays in the technical delivery of the ebook project have been due to the need to explore with Essex's strategic ICT partner, BT Syntegra, ways of implementing a front-line, public-facing service in a way that both satisfies security and other needs, and fits in with the many competing corporate demands of the county council.

However, other problems have been due simply to the technical complexities of providing an innovative service for which there is no existing blueprint.

So, some of the difficulties relating to the introduction of ebrary, for example, have been to do with ensuring secure access, including the use of firewalls and appropriate ports etc. However, others have been very practical - for example, use of ebrary requires the installation of a proprietary tool - the ebrary reader - on a PC before it can be accessed. Installation of this reader on to each of the 400 People's Network machines in Essex libraries - let alone the provision of the various links - is a major undertaking, and had to be coordinated with the "refresh" of equipment that was implemented during 2004.

Moreover, some aspects of the project have had to be put on hold for a different kind of technical problem. An example of this is the question of access via the library catalogue mentioned above: as both OverDrive and ebrary are US-based suppliers, their catalogue records are in the US MARC format. However, Essex Libraries currently uses UK MARC, and although it is possible to "translate" from one to the other, it was felt that it would be more sensible to await the introduction of the new "ELAN" library management system, with its accompanying move to MARC21, which is due to happen in early 2005.

\subsection{Distribution of PDAs}

Some initial work was carried out by the Project Team to make the PDAs easier to use as ebook readers. This consisted of customising buttons to provide shortcuts, 
and to hide the other, non-ebook, software such as Word/Excel, to try to avoid potential confusion .

Moreover, the Project Team and Essex Project staff discussed stylus from an adaptive technology perspective: it was acknowledged that people suffering from arthritis could have issues. There are styli available recommended by the US Arthritis Foundation ${ }^{\mathrm{x}}$. However, these cannot be purchased individually for the UK, and a trading account had to be set up, with minimum purchase quantities. There were insufficient funds in the project budget to be able to investigate this any further.

Prior to the distribution of PDAs to the target groups, appropriate local staff - such as mobile Library Managers, Access staff, etc. - had also carried out detailed preparatory work to identify potential users, explaining to them the type of service on offer. They then personally delivered the PDAs to individual readers, demonstrating how to use them and going through the support materials.

Support materials included a manual (Appendix 6) produced by the Project Team, exploiting the customised shortcuts described above. The manual also gave details of a helpline in the event of problems that could not be resolved through use of the manual. Users were also supplied with feedback questionnaires (Appendix 8).

\subsection{Promotion}

The ebooks promotion plan, developed by Essex Corporate Communications, included:

- An article in the January 2004 issue of Essex Matters (goes to 650,000 households in Essex);

- An article in the Essex Staff Magazine, "insx", also in January 2004;

- Press release, plus article on the Essex CC/libraries home page;

- A4 posters and A5 product cards for all libraries to promote ebrary, plus product cards to promote Overdrive to commuters and other target groups.

\section{Project, User and Staff Evaluations}

\subsection{Project Evaluation Critical Success Factors}

The Project Management and Research Team identified a range of Critical Success Factors (CSF) and Risk Analysis for the research from the perspective of the key stakeholders on the project (Appendix 3). This has provided a useful framework for managing processes, and as a basis for formal project evaluation at the end of the project. This document has also been circulated to the Advisory Board for their perusal.

\section{Summative Evaluation Findings}

The quarterly project reports and minutes from the Project and Essex Team meetings form the basis of tracking the formative progress of the project: specific progress and findings from implementation are included throughout this report.

Evaluation of CSF at the end of the project has produced the following findings: 
- $\quad$ the project has been completed in a timely manner, with regular reporting, disseminated to the Funder as well as to the project participants;

- $\quad$ The project overall has been able to return significant findings and recommendations, not just to the East of England region, but also to the UK public library domain as a whole. Proof of the project's high profile is verified via the dissemination list (see section 6);

- $\quad$ Progress in specific areas of the project have been greatly impeded due to problems with ICT implementation. Although some accounting for this was made in pre-project planning, the magnitude of the impact on the progress of the project could not have been predicted, as the project was a national, as well as regional pilot of new technology;

- In addition, some fairly important changes were made to the project plan, for instance in the area of user focus groups, technology implementation (especially ebrary), and piloting with visually-impaired people;

- $\quad$ The difficulties of managing the project across three distinct project partners were addressed in the project proposal by assigning specific roles to each. However, cross-partner communication and reporting remained a problem, with responsibility falling to a few team members, and individual workloads mitigating against the consistent participation of all;

- $\quad$ The project was not completed within budget. The original budget submitted to the LASER Foundation was reduced by almost $£ 7,000$, requiring significant matched investment by Essex Libraries. In addition, final negotiations with suppliers revealed hidden costs, largely due to differences between US/UK licensing and pricing models. In sum, a high-profile, high-impact project was run for relatively low cost;

- $\quad T h e$ project website, a major communication mechanism for the project, included reports and news. However, it did not include minutes, terms, action items, any of the formative documentation to track progress of the project. Initially, a weblog was developed to encourage interactive use of the website and partner communication. Unfortunately, but not unpredictably, this had to be abandoned through lack of use (a common occurrence for librarysponsored weblogs);

- $\quad$ Promotion and dissemination happened relatively late in the project, partly from delays in local technology implementation but also due to the amount of qualitative and quantitative data at the end of the project to be analysed.

Although some of the problems encountered during the project could be considered significant, it is important to remember that, as a feasibility project, the problems are findings in themselves and form the basis for recommendations to other public library authorities seeking to implement ebook technology.

\subsection{User and Staff Evaluation Aims and Methods}

The success or failure of ebook collections was evaluated using a number of methods, both in relation to ebook usage with library patrons and collection management with library professionals. Evaluations included both quantitative measures (including frequencies and data collected by the ebook vendors) and qualitative information gathered from both users and professionals. In essence, the ebook collections were evaluated in three ways:

- $\quad$ Evaluating user perceptions of the ebook collections;

- $\quad$ Evaluating professional perceptions of the ebook collections.

- $\quad$ Evaluating collection usage during the nine month period; 
These three areas provided a solid triangulative framework for evaluating the project, considering usage and reaction to collections from patrons and professionals.

\subsection{User perceptions of the ebook collections. Questionnaire 1: iPAQ user study}

Questionnaire 1 (see Appendix 8 for full text) was completed by 23 individuals who read ebooks on the iPAQ device between January and April 2004. In December 2003, prior to the survey, a small pilot study of the questionnaire was undertaken by the librarians involved in managing the collection. Following the pilot study, a number of questions were re-worded for clarity, and the questionnaire structure was more clearly delineated between quantitative (questions 5-14) and qualitative responses (questions 15-21).

Twenty three people took part in the trial. As can be seen from Table 1, just over half of these were aged $60+$ and more females took part than males. The oldest person to take part was 83 .

Table 1: Age and gender of users

$\begin{array}{cccc} & \text { Male } & \text { Female } & \text { Total } \\ \mathbf{2 1 - 3 0} & 2 & & 2 \\ \mathbf{4 1 - 5 0} & 1 & 2 & 3 \\ \mathbf{5 1 - 6 0} & 2 & 3 & 5 \\ \mathbf{6 0 +} & 4 & 9 & 13 \\ \text { Total } & 9 & 14 & 23\end{array}$

Approximately two thirds (16) of the people were retired. Two referred to themselves as housebound and five had a variety of jobs:

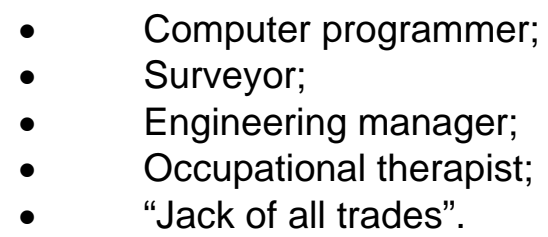

Books for reading on the iPAQ were downloaded onto the devices from the OverDrive ebook collection. The vast majority of titles, at the time of the trial, were available in Palm format. A much smaller number were available in Adobe ebook reader format, and, for technical reasons, these were pre-selected rather than chosen by the readers who responded to this question. Prior to reading, the individuals who took part in this questionnaire survey were asked to select titles. These were then loaded onto the iPAQs and lent out to readers. Beyond basic maintenance of the devices (e.g. recharging the battery, turning the device on and off), none of the individuals were responsible for downloading books themselves. This was the responsibility of the librarians involved, and their comments on managing the iPAQ collections are considered in section 5.4.

A range of fiction and non-fiction books in Palm format were read by the people taking part in the trial. Thirteen individuals read three or more titles on the iPAQ. Three Adobe titles were common to all participants, and the Palm titles were selected for these readers according to their expressed favourite genres, as with the other users. Most of the people taking part in the trial were avid readers with 17 of the 23 reading at least one book per week (see Figure 1). 
Figure 1: Reading habits of users

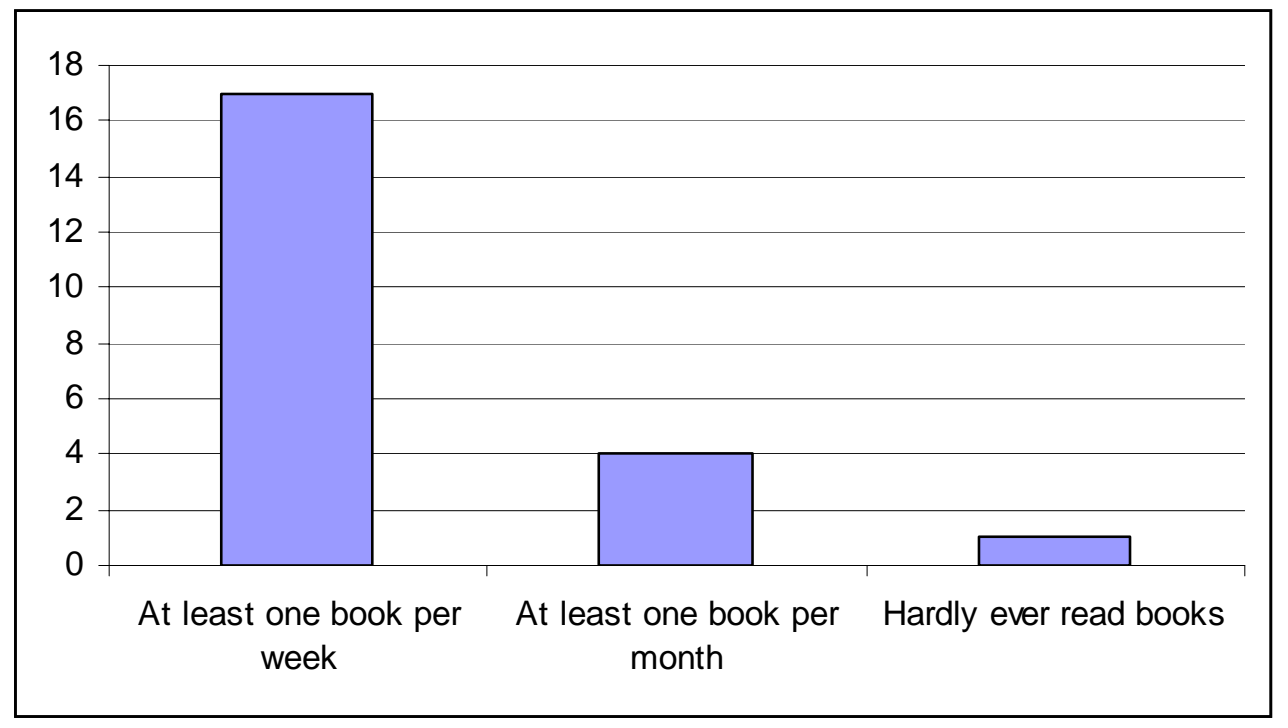

\section{Genres}

A variety of genres were read by the people taking part in the trial. Crime fiction, science fiction and autobiographies were especially popular. Respondents were limited in their selection of ebooks titles by the collection purchased from OverDrive. Comments on the quality of the collection were made, including respondent 6's assertion that [he] "would like to have been able to download some good books". As some research suggests that users are just not interested in reading web-based fiction, this statement indicates that more attractive titles might induce them to overcome the hesitation brought on by the technology. It is possible to surmise from respondent 6's completed questionnaire that lack of interest in the books he chose to read might have impacted negatively on his views of reading from the iPAQ. As an example of titles read, the following mixture of fiction genres, celebrity autobiography and gripping non-fiction was typical of individual selections:

The Rhythm Section (Mark Burnell)

The Quiller Memorandum (Adam Hall)

Beckham (David Beckham)

Until Proven Guilty (JA Jance)

Mrs. Dalloway (Virginia Woolf)

Run Jane Run (Maureen Tan)

Absolute Power (David Baldacci)

The Incredible Voyage (Tristan Jones)

Sharpe's Trafalgar (Bernard Cornwell)

Prey (Michael Crichton)

Conflict of Interest (Nancy Taylor Rosenberg)

Invaders from Earth (Robert Silverberg)

Fifteen of the 23 people taking part in the trial regularly used a computer. While all of these used computers at home the five employed people also used them at work. Only two people accessed them at the library. Most of the computer users had access to the internet (12 of the 15 users at home and all of the users at work).

\section{Functionality}


The respondents were asked to rate on a scale of 1 to 5 the ease of use of particular functions provided by the iPAQs ( 1 being very difficult, 5 very easy). Using Likert scaling, the combined results are shown in Table 3 . It can be seen that most functions were considered to be reasonably easy. However, there were a few individuals who found some tasks difficult, such as finding the book to read and using the central dial.

\section{Table 2: Ease of use of iPAQ}

\section{About the iPAQ}

Comfort of holding the iPAC

On and off switch

Finding the book to read

The stylus

Central dial

Reading the book

\section{Likert Score}

4.5

3.4

4.2

3.9

3.9

3.8

3.9

Moving through the book using:

The stylus

The central dial

Icons on the lower right hand on the screen

\section{Positive reactions}

Respondents were asked what they liked about reading on the iPAQs. The replies can be sorted into two main categories - convenience and readability. In terms of convenience, as the selection of comments below demonstrate, respondents were generally impressed with the small size of the iPAQ devices and their ability to store several books on the same device. Portability was commented on, with several respondents positively commenting on the 'size of the machine' and 'always handy e.g. in a doctor's waiting room'. Another respondent considered that the iPAQ was 'a handy size, [there is] no need to hold the book open, ideal on journeys'. One individual made reference to the 'novelty value' of reading an electronic book. Six respondents commented more specifically on the reading experience, with comments concerning the 'clear type face' and 'clear text'. Backlighting of text was also commented on, with two respondents indicating ease of use in poorly lit areas ('easy to use in poor light areas' [9]; 'back lighting of screen an advantage').

Thirteen respondents indicated that the ebooks offered advantages over traditional pbooks. Eight respondents considered that ebooks offered no advantages over pbooks. Responses correlated with the 'convenience' aspects noted by respondents when asked what they liked about the devices. Portability was considered the greatest advantage compared to pbooks in terms of size, weight and the ability to carry several book titles on the same device. Selected comments include:

Ease of transport. I seem to spend a lot of time waiting in hospitals or travelling.

Easy to pick up and find your place in the book currently being read.

Being able to take several books without having to carry them all.

\section{Negative reactions}


Eighteen respondents noted their dislikes about reading from the iPAQ. Recurring negative comments included the battery life, small screen and lack of tactility when compared with pbooks. Respondents 3 and 10 drew reference to problems faced by an arthritis sufferer and an individual suffering hand cramps when using the iPAQ. Mobipocket, the format now favoured by OverDrive over Palm, but unavailable at the time of this part of the project, has an automatic scrolling facility which overcomes the need to continually change pages manually, and so would mitigate some of the problems described here.

For some respondents, the reading experience was inferior to pbooks in terms of readability and the tactile feel of paper books. Comments include 'reading the book didn't give a nice flow to the story', 'found it hard to re-read a page ... like to read by glancing ahead on the double spread of a book', and 'like to turn pages'. The tactile pleasures of the pbook were also missed by respondent 4 ('not as tactile as a real book'), and respondent 15 ('used to books and the feel of them').

The small screen size was also commented on in a negative sense by several respondents - 'I read quickly and was irritated by the flicker of moving the small pages on', and 'did not appeal to me, as a very small section appears at a time'. However, respondent 1 did get to grips with the small display - 'a fairly long learning curve to concentrate on small page size. However, after this period I found it easy'. Comments from two respondents went further:

Vulnerability of screen - needs a case (soft on hand); 2. A little slippery to hold; 3. Central dial uncomfortable to use over a long period; 4 . Battery runs down too quickly; 5. Seems better for short stories, essays etc and not for books with many pages; 6 . No pictures and diagrams loaded except for the Poirot story and this was too small to see; 7. Would need to download to a computer for no 6.

Had to charge the iPAQ more often than convenient. Cannot see enough on the screen at once - slows down the reading process. Cannot 'flick' between pages, for $x$ ref purposes.

\section{The reading experience}

Respondents were specifically asked how their reading experience differed when using the iPAQ. To some extent, the essential differences between reading a pbook and an ebook on the iPAQ can be extrapolated from responses considering likes and dislikes. Responses could be grouped into three broad categories:

- $\quad$ usage (cannot safely be 'read in the bath'; others also made the same point);

- $\quad$ traditional reading experience versus a new reading experience (tactile sensation of feeling and reading books, a fear expressed by respondent 15 that pbooks were part of her life, and that she would 'miss them if they changed');

- $\quad$ iPAQ format, and the small size of the screen and battery life.

Respondents were asked to consider the advantages and disadvantages of reading from iPAQs as opposed to traditional pbooks. One substantial potential disadvantage noted by respondent 15 considered that ebooks might mean the 'end of libraries such as Loughton and Debden' - effectively new technology supplanting traditional library usage rather perhaps than providing a supplementary service. Two respondents felt that reading pbooks was a more 'enjoyable' experience, with a telling comment from 
respondent 12 that reading from the iPAQ 'imposes its pressure on the experience in a way that the paper book does not'. Respondent 7, while commenting on the benefits of clear text and the backlight, also referred to the "pressure to read before the page clears or turns off'. A number of respondents made specific reference to the problem of reading from a small screen (in terms of the overall size, paging up and down and 'following' the story).

If we take the answers as a whole, the prime disadvantage of reading from an iPAQ can be best summed up as a lack of immersion in the reading experience (respondent 11 made exactly this point, it being apparently 'harder to get immersed in an iPAQ'), while respondent 10 considered that the ebook 'is a completely different concept'. This point is unusual in that this respondent did not make a straight comparison between reading ebooks and pbooks. It is also obvious from responses that the technology provided a distraction to some from the act of reading, and imposed on them a sense of pressure to read in a different fashion than they would with pbooks (e.g. referring back in the text for clarification of some point was apparently more difficult on the iPAQ). Other comments included:

Printed paper books are visually better (palm being closest software to book), but iPAQ is good enough in the light of added portability.

Clear print on good back light iPAQ. But seems to have a pressure to read before page clears or turns off.

It is a completely different concept. Would appeal more to young people, though might help elderly who cannot hold a large book (probably too small though).

The final question allowed respondents the opportunity to make general comments on their experience of reading ebooks. Most themes were evident in answers to other questions - battery life, the greater tactile pleasures of pbook reading and lack of immersion in ebook stories, problems faced after 'getting lost' on the iPAQ and the range of ebook titles available for perusal. It is however interesting to note that several respondents 'enjoyed' the experience of trying out ebooks on the IPAQ devices, and it is obviously the case from studying completed questionnaires that the majority of respondents found the iPAQs interesting enough to take seriously even if they disliked reading from them. Comments included:

I enjoyed the experience, and I feel with time I could get more used to the experience.

Unfortunately, the book supplied was one that I would not normally read. Would like to try with a book of my usual sort. It would be interesting to develop a larger machine, to reproduce a whole page, paperback size with variable print size and a stand to hold it up. NB The battery goes down v. quickly, even when not in use.

Money would be better spent on improving stocks of books until technology improves in this area. Perhaps talking books are the way forward with facility to listen through headphones.

\section{Conclusions}

The indicative findings of this questionnaire survey raise a number of issues which perhaps mitigate against using iPAQ devices for ebook collections. Responses to the questionnaire indicate that the majority of the 23 participants took the experience seriously, and while positives were noted (portability, clear text on screen), the 
overall tone emphasised the negatives. Most of the respondents made straight comparisons between ebook and pbook formats, and although the questionnaire asked for comments on comparability (advantages and disadvantages of ebooks versus pbooks), the views of respondent 10 - that in effect ebook reading is a 'completely different concept' merits some attention. The iPAQ devices which we used for the survey are not primarily designed for ebooks, and while criticisms were noted in regard to the small screen and 'fiddly' nature of navigating the devices, it is perhaps the case that patrons borrowing ebooks for their own PDAs would be intrinsically more comfortable using the devices. Additionally, it is also obvious from this survey that marketing new ebook collections should emphasise their supplementary benefits and avoid patrons reaching conclusions that ebooks are set to supplant pbook collections. The 'new' in this case will almost certainly never replace the 'old'. The OverDrive collection included 250 titles, and it is evident from this survey that some individuals did not find anything of great interest to read - the obvious point being that where public libraries choose to invest in ebook technologies, they will need to invest in good collections, and with an ongoing commitment. Returning to the devices themselves, using iPAQs for ebook collections raised a number of concerns about battery life, and the need to recharge the devices regularly. It is apparent from this survey that this was a major issue, and apparently overrode some of the benefits of portability which were noted. Beyond the problem of drained batteries and the need to reformat machines when the battery ran out, the iPAQs offered no serious reliability issues, and all the devices bought in 2003 were working at the end of the trial.

\subsection{Professional perceptions of the ebook collections. Focus group, April 18 2004.}

Reactions to the iPAQ ebook trial were obtained from library professionals who were involved in managing the collection. Information gathering comprised bimonthly meetings with the Essex Project Team, as well as a final meeting to gather summative evaluation. In summary, information was sought on the following aspects:

- $\quad$ The costs, direct and indirect, of introducing and maintaining ebook collections;

- $\quad$ Opinions on the quality of the collections from librarians;

- $\quad$ Opinions on the quality of the products (problems, how they were solved; benefits);

- $\quad$ Opinions on the ebrary, OverDrive and portable ebook models (i.e. do the present ebook models cost too much? What degree of flexibility do they offer libraries? What are the calculated costs of ebook versus pbook?);

Feedback from library professionals can be considered broadly in relation to strengths and weaknesses. Following discussion at our final meeting in April 2004 these can be summed up thus:

\section{Strengths of ebook collections}

- $\quad$ Portability;

- $\quad$ Positive impact of new technology;

- $\quad$ Ease of use within existing mobile library service;

- Anonymity.

Weaknesses of ebook collections 
- $\quad$ Battery life, and recharging;

- $\quad$ Re-formatting devices after battery has run out;

- $\quad$ Users loading third-party applications onto the devices;

- $\quad$ Lack of Broadband connection for some users.

Following the closure of a branch library in Essex in the summer of 2003, residents of the affected village viewed the ebooks that were available on the mobile library service with a rather jaundiced view - one resident was of the opinion that ebooks were a 'plot to get rid of the printed book'. However, beyond this rather acidic comment, librarians reported a generally positive response to the ebooks that correlates with the findings of the questionnaire survey considered in the previous section. With regard to the mobile library service, librarians considered that this was a successful way of getting ebook collections started as a complimentary service to existing pbook collections. Where library patrons were not taken with ebooks, there was at least a sense that the potential for ebook collections was apparent from comments. The novelty value of using new technology was also apparent, with librarians noting a degree of curiosity from patrons to the ebooks whether they decided to use the iPAQs for reading or not.

In one aspect of use not considered prior to the study, librarians reported that the ebooks were popular with individuals who felt stigmatised by publicly reading books that related to personal or mental health problems. ebook collections might be aimed at such individuals.

Ebooks come with a range of limitations that have to be considered prior to starting collections. The problems still lie primarily with portable devices, and where they are owned by the library authority (as opposed to patrons downloading books onto their own devices) a number of issues arise. Librarians noted the tendency for the IPAQ batteries to run out quickly, and hence the need to re-load books onto the devices after re-charging. After battery life was noted as a problem, librarians encouraged users to plug the devices into the mains electricity supply. While this indeed negates the problems of battery life, it is questionable how happy users would be in the long run to pay for electricity to help them read books, and whether the 'portability' benefits of the format would suffer accordingly.

The first generation of dedicated portable ebooks (e.g. Rocket eBook, SoftBook) have become obsolete, and the iPAQ devices are not primarily designed for reading. Problems were noted with the devices, most notably from individuals who lacked the dexterity to operate them. For example, one of the librarians noted the problems a patron suffering from arthritis found using the iPAQ stylus and central navigating button. Additionally, comments were made concerning the reading experience itself, and particularly with the size of screen and 'flickering text'. One suggestion from a patron was that ebooks would be best read on 'bigger, better devices designed for books' (use of PC tablets for future research would be beneficial).

Essex offered telephone support to patrons via Library Direct, from which customers could seek help when things went wrong, as well as an email link from the main web site. Two calls were received via telephone, and four email enquiries (including an individual asking how to convert Adobe's e-book format into plain text for printing and binding). Beyond problems with batteries, no more substantive problems were raised by patrons. One individual had made some efforts to install various Flash games on the iPAQ, which raises the issue as to what extent the devices should be 'locked' to prevent unauthorised usage. 
Due to battery life, the librarians were able to draw some very general conclusions on how straightforward ebook software was to install. At the meeting, the Adobe Reader was judged to be 'temperamental', Palm Reader 'quite straightforward' and MobiPocket 'much simpler but not entirely intuitive'. 


\subsection{User perceptions of the ebook collections. Questionnaire 2: OverDrive and ebrary user study}

Questionnaire 2 (see Appendix 9) is being used to gather information on the webbased OverDrive and ebrary collections. Due to data protection issues concerning identification of patrons using web-based collections, questionnaire 2 is hosted on the web, with a link from the ebook collection homepage. Responses are being collected and collated over a six-month period as the collections are rolled out. Analysis of Questionnaire 2 data will be published separately to this report, later in early 2005.

\subsection{Quantitative data on the OverDrive and ebrary collections.}

Data continues to be collected on the following:

- $\quad$ The total number of titles available on ebook collections during the period;

- $\quad$ The total number of users over the nine month period;

- $\quad$ The total number of repeat users over the nine month period;

- $\quad$ The total number of loans over the nine month period (perhaps growing as the service becomes better known, or not). To date we already know the following from OverDrive statistics: December 12003 - April 30 2004: 120 days, 134 checkouts of 88 titles; May 12004 - July 15 2004: 92 days, 76 checkouts of 54 titles.

- $\quad$ The total number of loans for specific book genres (demonstrating which part of the ebook collections are most popular, and which are least popular);

- $\quad$ The total number of library patrons accessing the ebook collections from home.

Due to the aforementioned problems with installing the collections, analysis of this data will be considered in a separate report later in 2004 along with the results of questionnaire 2 .

\section{Dissemination}

While the preponderance of dissemination activity has occurred after project close, the research has received publicity from a range of sources both in the UK and abroad. Penny Garrod, a member of the external advisory board, considered the project in an Ariadne article ${ }^{\mathrm{xi}}$, and also in her E-books in UK Public libraries...the story so far presentation given at the Co-South ebooks meeting in April $2003^{\mathrm{xii}}$. The project is also prominently listed, with a link to the web site, from the UKOLN 'Public Library Networking Focus' page ${ }^{\text {xiii }}$. OverDrive have also publicised the project in various press releases ${ }^{\text {xiv }}$, and this was picked up by Lycos (who referred to 'Essex County'- page since deleted). Additionally, the project was publicised in 'Info@uk' and on the joint Loughborough University-Cranfield University 'epicentre' website ${ }^{\mathrm{xvi}}$.

Since project close in Spring 2004, the following presentations have been or will be made:

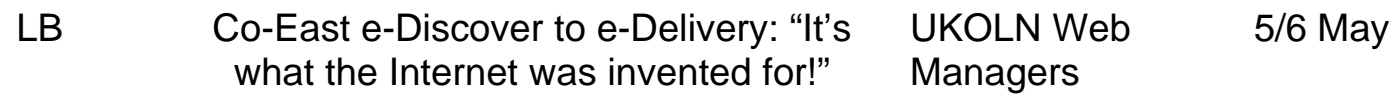




\begin{tabular}{|c|c|c|c|}
\hline & & Conference. Bath & \\
\hline LB/MP & $\begin{array}{c}\text { Putting the 'e' in Essex: a public library } \\
\text { feasibility study }\end{array}$ & $\begin{array}{l}\text { NAG: eBooks } \\
\text { Conference. } \\
\text { London }\end{array}$ & 19 May \\
\hline LB & $\begin{array}{l}\text { Sharing e-Books: behind the electrified } \\
\text { fence }\end{array}$ & $\begin{array}{l}\text { FIL Conference. } \\
\text { Sheffield }\end{array}$ & 12-14 July \\
\hline LB & $\begin{array}{l}\text { Discovery to Delivery in the East of } \\
\text { England: the Co-East Partnership }\end{array}$ & $\begin{array}{l}\text { JISC RSC- } \\
\text { Eastern Region. } \\
\text { Colchester }\end{array}$ & 22 July \\
\hline MP & $\begin{array}{l}\text { e-Books in public libraries: a feasibility } \\
\text { study }\end{array}$ & $\begin{array}{l}\text { Essex/Suffolk } \\
\text { Day }\end{array}$ & 26 May \\
\hline
\end{tabular}

LB/MP

SCURL

1 October

Additionally, we are preparing articles for publication considering the major ICT issues arising from this research and a contextual paper considering the questionnaire results contained in section 5 of this report. These two papers are being submitted to JOLIS and Public Library Journal in August and September 2004. Further dissemination considering the web-based collections will follow after publication of the supplement to this final report. Finally, the Co-East partnership is planning an ebook event as part of the Co-East AGM in February 2005, and the Project Team is currently discussing a publication with Facet Publishing.

\section{Final Report: Summary of Findings}

- $\quad$ There was no evidence from this research that ebook collections are unsuited to public libraries per se. While a greater emphasis in the UK has been placed on developing ebook collections in academic libraries (reflecting a perception that textbooks and reference books are potentially better suited for ebook formats), there is no evidence from this research that ebook fiction collections should be viewed wholly as a non-starter. In this sense, our research does not support the apparently common-held belief (and one based on little hard evidence) that ebook fiction collections are in some sense bound to be less popular than ebook non-fiction collections. However, developing and offering the 'right' ebook collection is somewhat more involved.

- $\quad$ The size and format of iPAQs is not ideally suited for reading, and the results of questionnaire 1 indicate that while readers enjoyed trialing the devices, they did not generally enjoy the reading experience. The increasing popularity of A4-size notepads and tablets might potentially offer a far superior platform for reading, and they could be considered as a future possibility for use in public libraries. The findings of questionnaire 2 will provide an opportunity to compare the merits of PDA-based collections with the web-based collections, OverDrive and ebrary.

- $\quad$ Patrons made positive comments on the portability of the mobile technology and the ability to change font size so titles could be converted to large print. The major concern related to short battery life, and this impacted negatively on readability and portability (i.e. when the battery runs out, the titles on the iPAQ are lost). We noted the potential for greater 'private' reading from 
handheld devices, and in particular for those patrons who felt embarrassed about being seen to loan books (in our case, relating to mental health issues). Our iPAQ research was limited to a five month period, and during this time we encountered no problems with the devices in terms of reliability or breakages. However, an ongoing commitment to repair, replace or upgrade devices should be expected, as could perhaps more commonplace irritations of replacing lost styli. It seems sensible to offer a collection readable on PDAs to those who own them via, for example, the OverDrive collection we purchased. However, in our opinion, the costs of offering public library PDA collections (where the library owns and maintains hardware) outweigh the benefits.

- $\quad$ Ebook collections potentially offer public libraries an attractive supplementary service, and the growing amount of titles available allows substantive and varied collections. Essex Librarians and patrons viewed the ebook collection with interest, and marketing appealed to a number of users with special needs (for example, a housebound user who has made substantial use of the OverDrive web-based collection - detail will follow in a supplement to the Final Report). We have noted that reaction to the collection was less positive in some quarters, and in particular where local branch libraries had closed. It is therefore important to market new ebook collections as a supplementary service, and not allowing users to draw conclusions that collections are being developed to supplant pbook collections.

- $\quad$ The two supply models adopted for this research offer costs and benefits respectively. OverDrive offer libraries the ability to build up collections based on purchase of individual titles which are then loaned to patrons on a one copy per user basis. This system therefore replicates existing pbook borrowing. The OverDrive collection was delivered on the IPAQ devices and on the Internet to remote users. ebrary works on purchasing a complete collection which is then available on a concurrent basis to patrons with Internet access and those choosing to read from PCs in the library.

- $\quad$ The OverDrive collection proved relatively straightforward to adopt, and was used successfully for the iPAQ trial. An issue which became apparent concerned ebook formats. During the course of the nine month period OverDrive migrated from the Palm format to the MobiPocket format. OverDrive were quite willing to replace the Palm format titles that Essex had bought, but this raises a fundamental problem which has dogged ebook development since 1998. Formats have become redundant, and a major issue which our research encountered is the potential to develop collections which could become obsolescent. This has obvious negative impacts on libraries, and also potentially with users who might have to learn new procedures for downloading titles.

- $\quad$ The ebrary model should ostensibly make life easier for the librarian, but certain issues concerning installation, usage, and collection bundling proved problematic. ebrary was developed for use in the USA where 'accesses' are bought by individual libraries. While it is available in the UK, the model proved difficult to adopt in Essex, where registered users can borrow from all libraries, and not specific libraries. Finding an accommodation for this product proved difficult and time-consuming. Therefore, ebrary is not currently wellsuited to UK usage. As we considered in section 4.6, the financial commitment involved with adapting Essex's PCs to support ebrary potentially outweigh the benefits of offering this collection to the public. Moreover, 
purchasing collections results in the same problem that arises from the purchase of electronic journals databases: only a fraction of the titles provided may actually be of interest to a public library audience.

- Installation of ebook software was wholly reliant on liaison with Essex's corporate ICT partner, and this process was subject to various delays over the year. Delays were due mainly to satisfying security issues and installing software (for example, the ebrary reader was installed on all 400 of Essex's People's Network machines during mid 2004). Our experience is not unusual, with members of the Advisory Board also referring to delays in implementation due to ongoing discussions with corporate ICT partners. However, while problems were eventually resolved, the pace of progress was frustrating at times. Public libraries who are considering ebook collections should not underestimate the needs and requirements of ICT partners, plus the indirect costs that are racked up with installation.

\section{Guidelines for Public Library Implementation}

Based on our project findings, we would suggest the following approach to implementation of ebooks and mobile technology in a public library authority:

\section{Product Selection}

\section{Mobile technology versus web-based collections}

The decision to adopt mobile technology (PDAs) presents certain challenges, as alluded to in the summary of findings. While the devices provide a compact portable platform for selected ebooks, the fact that PDAs are not designed primarily for reading creates problems. Librarians and readers noted short battery life (not necessarily a problem for ordinary use of PDAs, but a disadvantage for long periods of reading), and devices need to be 'locked down' to stop usage of other programs or accidentally deleting titles. Despite 'locking down', it was noted that one user had managed to download Flash games onto a device. PDAs are expensive to purchase, and require micro-management of collections loaded onto them. Replacing broken machines would present additional costs. Implementing publicly-available PDA collections with the present technology is, in our opinion, unviable unless libraries can fully justify purchase for specific user groups. However, there may be scope to use other forms of mobile technology, such as notepads, laptops, etc.

Web-based ebook collections offer libraries an increasingly attractive service for public lending. Our experience of OverDrive has been positive, with the company showing a willingness to meet Essex's needs and take an active interest in promoting the collection. OverDrive's first working web-based collection in the UK was developed as part of this research. Additionally, OverDrive were willing to offer MobiPocket format titles at no extra cost when they migrated from Palm to MobiPocket during the course of this research. Despite this, public libraries in the UK should be prepared when considering ebook collections to consider the implications of the ongoing 'format wars'.

Implementation of PDA collections:

- $\quad$ Best aimed at special user groups; 
- $\quad$ Their cost and micro-management mitigates against open public lending;

- $\quad$ Best used in conjunction with a web-based ebook collection such as OverDrive;

- $\quad$ Calculate costs of purchasing devices and on-costs such as upgrading or replacing them plus incidental costs such as replacing styli.

Implementation of web-based collections:

- $\quad$ Identify a vendor who has experience of working in the UK, and who is willing to get closely involved with development. This point is absolutely crucial in terms of technical discussions with the corporate ICT provider.

- $\quad$ OverDrive's collection is based on the traditional one user - one copy system. While the ebrary model apparently offers greater freedom with its concurrent access model, we consider that the 'traditional' model has in fact been far easier to implement in Essex.

- $\quad$ Choose a collection that can be delivered to remote PCs, users' PDAs and other portable media such as smartphones. While PDA collections might be limited to special user groups, as they were in this research, flexibility should allow public libraries to experiment with different methods of delivery.

- $\quad$ ebook formats continue to evolve, and with them format wars. Librarians are well advised to consider collections which will remain viable in the foreseeable future, as well as reaching an understanding which formats work on particular hardware devices.

\section{Product negotiation}

ebook collection (licenses, stock supply, costs, US suppliers)

The above comments, regarding the variety of formats, methods of delivery, and so on will clearly impinge on the way that public libraries approach the question of negotiation with suppliers :

Suppliers should be able to demonstrate that they are able to exploit all the advantages of ebooks in relation to simplicity of supply/invoicing and other costs of acquisition, including cataloguing;

Consequently, the supplier's physical location should not normally need to be a factor when working with ebooks, as the costs incurred in dealing with the overseas supply of pbooks do not arise. So, the fact that many ebook suppliers are based in the USA should not be a significant problem;

However, suppliers do need to be able to show not only that they have the technological means to deal with all aspects of digital rights management and related matters, but also that the rights themselves relate to the UK as well as the USA;

- In addition, foreign suppliers and their third party agents must establish clear, efficient lines of communication with UK public libraries in order to ensure clarity of contract terms and timely problem-solving; 
The cost of ebooks varies considerably: some suppliers prices are based on the cost of the hardback pbook, others on the cost of the paperback pbook, while some seem to have no relationship to pbooks at all.

\section{Mobile technology}

The choice and purchase of suitable mobile technology for use with ebooks is fraught with all of the problems linked to the rapidly changing environment for both hardware and software:

Compatibility between each ebook format and different kind of hardware is constantly changing, as is the cost and appropriateness of each different hardware format. At the start of this project, dedicated ebook readers were still (at least theoretically) available, but PDAs seemed to offer a better way forward as a delivery vehicle. If the project had started 18 months later, it is likely that tablet PCs would have been chosen;

However, some things change less quickly - when the iPAQ 1910s were purchased for this project, the release date for Adobe's Digital Rights Management package for Pocket PCs had just been postponed. Eighteen months later, the software has still not appeared, meaning that the only Adobe titles that the iPAQs can read are those that are out of copyright.

\section{Technical implementation}

Implementing the collections proved to be the greatest burden on time and resources during this research, and is an issue which should be approached with care. Our experience was perhaps made more awkward by installing two ebook collections that operate differently, and it is probably the case that purchasing and installing a single collection would not prove as time-consuming. Public libraries who do not rely on a corporate ICT provider might also be better able to implement collections in a shorter timescale. Our suggestions:

- $\quad$ Public libraries should ascertain before collections are purchased what the ICT provider will approximately charge for implementation work. In project planning, we did not make adequate provision for this, and the financial burden was eventually met by Essex County Libraries. Installing ebrary readers on all People's Network machines incurred a significant expense;

- $\quad$ Corporate ICT providers have many competing demands, and libraries intending to purchase collections should factor in adequate time to accommodate this. Once again, during project planning in April 2003 we failed to anticipate the amount of time that was required to consider security/access issues, as well as more practical issues relating to installing software.

\section{Collection Development}

Public Librarians are faced with a couple of fundamental choices regarding collection development: 
Do they want to buy by title, or by collection?

Will ebooks be accessible only via PC, or by mobile technology as well?

Questions that then arise are very similar to those for pbook collection development:

If they want to buy by title, which formats are they going to include?

If buying a collection, do they have to buy a lot of material that would not normally have been considered?

How much of the material available is aimed at the public library reader?

How much of the material is aimed at the UK reader?

How often are new titles released?

All of which assumes that some preparatory work has already been done in identifying target audiences in terms of age, interests, and so on. Essentially, libraries should start thinking of a collection development strategy which integrates print and electronic titles in the selection process.

\section{Staff Training/Champions}

We were fortunate in this research to identify a number of librarians who were interested in ebooks and willing to help us trial the iPAQs. Their feedback at all stages of the research was extremely useful. Our recommendations include:

- If possible, a 'champion' should be identified with collection development from the beginning. Other public libraries have well-known 'champions' who have been able to promote the services widely - for example - Ian Sutton at Blackburn with Darwen and Monica Vidana at Richmond;

- $\quad$ Library staff should be involved with the collections from the start, and should be given adequate time to trial ebooks themselves before collections are rolled out. In our case, the manual and drafts of questionnaire 1 were piloted by the librarians involved, and this proved beneficial;

- $\quad$ Use of PDAs involves micro-management both in terms of maintaining the devices (e.g. loading and re-loading titles), and showing users how the devices work. A remote helpline was also used to help users when they encountered difficulties. Documentation for the helpline was an additional task that needed attention before collections were rolled out.

\section{Promotion}

Promotion and marketing of ebooks - as for all electronic resources - is problematic. Traditional promotional materials such as posters and leaflets can provide some exposure, but their ability to get across to the public precisely what ebooks and their advantages are seems to be limited. This isn't helped by the fact that ebooks can take many forms. Gaining access to an ebrary-type product on a library PC is clearly different from "borrowing" an OverDrive title and reading it on the train, but promoting these two things under the ebook umbrella can be confusing. 
Perhaps the single most effective way of promoting ebooks is to add their records (and downloading link buttons) to the library catalogue. In this way, many readers will come across them as part of their "normal" use of the library. Similarly, highlighting on the library/council website and provision of hyperlinks will also enable readers who might not otherwise come across ebooks to discover them.

\section{Evaluation}

Evaluation should not begin with the user questionnaire or focus group after the experimental purchase of an ebook collection. Electronic resources are too costly, their implementation too time-consuming for potential use to be measured only after the fact.

Evaluation begins with market research or community-profiling. Only libraries familiar with their populations can calculate the appropriate risks/benefits of implementing new electronic services. We found the Essex Project Team's knowledge of local user groups invaluable to identifying the potential receptivity of the technology. Therefore the following considerations should be included in a user evaluation plan:

- $\quad$ Market or community profiling, to be updated on a regular basis;

- $\quad$ Staff training in conducting interviews, developing questionnaires, holding focus groups (even if this process is to be outsourced, knowledgeable staff members will be able to evaluate the work of consultants);

- $\quad$ Identification of particular target groups for evaluation purpose;

- $\quad$ Provision of mechanisms for general feedback, such as web-based questionnaires (along with periodic incentives for their completion, such as book tokens, etc);

- $\quad$ Regular schedule of evaluation, with corresponding service, supplier, content, and contract review;

- $\quad$ Statistical packages which will provide quantitative feedback on use;

- $\quad$ Dissemination of evaluation results (use in supporting proposals, service plans and audits; promotion etc).

Although when we talk of evaluation, more often than not we are referring to users, it is important to remember that regular evaluation extends to:

- $\quad$ the collection itself (popularity, pertinence, and timeliness of titles);

- $\quad$ the service delivery (periodic reviews that the resources are being used/promoted to their best advantage; that they are being used at all and why/why not);

- $\quad$ staff (adapting to new technology; modelling use of new services with users; feedback from staff on user uptake).

Finally, evaluation in all of the above areas may lead to renewal or termination of the ebooks collection from a particular supplier. In this case, exit and/or migration strategies should be in place to ensure a seamless transfer of service. 


\section{References}

i Dearnley, J. \& C. McKnight, 2002. The People's Network, Public Libraries and ebooks: specification for baseline intelligence-gathering work. < http://www.mla.gov.uk/documents/re177rep.pdf $>$, [accessed 29.7.04].

${ }^{\text {ii } B l a c k b u r n ~ w i t h ~ D a r w e n ~ B o r o u g h ~ C o u n c i l: ~ e-b o o k s . ~<~}$ http://library.blackburnworld.com/reading/ebooks/index.htm >, [accessed 29.7.04].

iii E-book and E-audio Services in Richmond.

$<$ http://www.richmond.gov.uk/depts/opps/eal/leisure/libraries/pn/ebooks/default.htm $>$, [accessed 29.7.04].

${ }^{\text {iv }}$ Vidana, M. e-books in public libraries, Update, May 2003. <

http://www.cilip.org.uk/update/issues/may03/article4may.html >, [accessed 3.8.04].

${ }^{\mathrm{v}}$ McKnight, C. \& J. Dearnley. Electronic Book Use in a Public Library , Journal of Librarianship and Information Science, 35(4), December 2003, 235-242.

${ }^{\text {vi }}$ Craig, C. E., 2003. "Lending” institutions: the impact of the e-book on the American library system, University of Illinois Law Review, 2003(4), December 2003. < http://home.law.uiuc.edu/lrev/publications/2000s/2003/2003 4/craig.pdf $>$, [accessed 29.7.04].

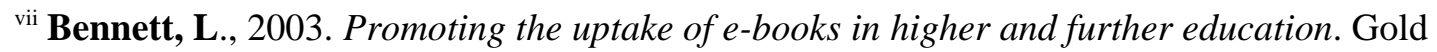
Leaf Consultants for the Joint Information Services Committee. $<$ http://www.jisc.ac.uk/uploaded_documents/PromotingeBooksReportB.pdf $>$, [accessed 29.7.04].

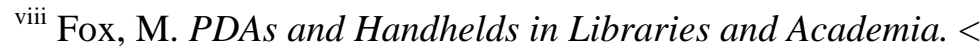
http://web.simmons.edu/ fox/PDA.html\#pr >, 2003, [accessed 1.8.04].

${ }^{\text {ix }}$ Bennett, L., 2003. Promoting the uptake of e-books in higher and further education. Gold Leaf Consultants for the Joint Information Services Committee. < http://www.jisc.ac.uk/uploaded documents/PromotingeBooksReportB.pdf $>$, [accessed 29.7.04].

${ }^{\mathrm{x}}$ Stylisource. $<$ http://www.stylisource.com/detail.asp?product_ID=t1042 $>$, [accessed 1.8.04].

${ }^{x i}$ Garrod, P. Ebooks in UK libraries: where are we now? Ariadne, 2003, 37. < http://www.ariadne.ac.uk/issue37/garrod/ >, [accessed 1.8.04].

${ }^{\text {xii }}$ Garrod, P. E-Books in UK Public Libraries: the story so far. < http://www.ukoln.ac.uk/public/present/ebookspublibs/ppt-2000/intro files/frame.htm >, 24 March 2003, [accessed 1.8.04].

xiii Public Library Network Focus. < http://www.ukoln.ac.uk/public/ >, [accessed 1.8.04].

${ }^{x i v}$ Small Community Library becomes a high-flying technology leader. < http://www.overdrive.com/news/pr/07292003.asp >, [accessed 1.8.04]. 
xvInfo@UK Bulletin. < http://www.britishcouncil.org/info@uk/aug03/newpubs.htm >, August 2003, [accessed 1.8.04].

${ }^{\text {xvi }}$ EPICentre < http://www.epicentre-research.org/projects.html $>$, [accessed 1.8.04]. 